\title{
İzole ulna cisim kırıklarında konservatif ve cerrahi tedavi yöntemlerinin karşılaştırılması
}

\section{Comparison of conservative and surgical treatment methods in isolated ulna shaft fractures}

\author{
Tolga TOLUNAY ${ }^{1 *}$, Mehmet Orçun AKKURT ${ }^{2}$ \\ 'Gazi Üniversitesi Tıp Fakültesi, Ortopedi ve Travmatoloji Anabilim Dalı, Ankara/Turkey \\ ${ }^{2}$ Yenimahalle Eğitim ve Araştırma Hastanesi, Ortopedi ve Travmatoloji Kliniği, Ankara/ Turkey
}

\section{öz}

Amaç: Izole ulna cisim kırıklarının tedavisinde hem konservatif hem de cerrahi metodlar önerilmiştir. Çalışmanın amacı izole ulna cisim kırıklarının optimal tedavisini ve kırık iyileşmesini etkileyen faktörleri araştırmaktır.

Gereç ve Yöntemler: Çalışmaya 2013-2016 yılları arasında hastanemize başvurmuş izole ulna cisim kırıklı 43 hasta alındı. Hastalar konservatif tedavi edilen ve cerrahi olarak tedavi edilen olmak üzere 2 grupta incelendi. Sonuçların değerlendirilmesinde eklem hareket açıklığı, kavrama gücü, fonksiyonel ve radyolojik sonuçlar kullanıldı. Ağrı vizuel analog skala (VAS) ile değerlendirildi. Kavrama gücüne ise el dinamometresiyle hasta otururken ve dirsek 90 derece fleksiyonda bakıldı. Fonksiyonel sonuçlara kol, omuz el sorunları skorlaması (DASH Skoru) ile bakıılı.

Bulgular: Konservatif tedavi edilen grupta 23 hasta, cerrahi tedavi edilen grupta 20 hasta bulunmaktaydı. Her 2 grup arasında yaş, cinsiyet dağılımı, kırık paterni, yaralanma mekanizması ve kırık lokasyonu açısından fark saptanmadı. Her 2 grup arasında VAS skoru, kavrama gücü, DASH skoru ve kaynama açısından da fark saptanmadı. Konservatif tedavi edilen grupta kaynama süresi ortalama $12 \pm 1,04$ haftayken cerrahi olarak tedavi edilen grupta kaynama süresi ortalama $17 \pm 1,16$ haftaydı $(p=0,586)$. Her 2 grup arasında dirsek ve el bileği eklem hareket açıklığı ve komplikasyonlar açısından da fark saptanmadı.

Sonuç: Çalışmamızda cerrahi olarak tedavi edilen hastaların konservatif olarak tedavi edilen hastalardan fonksiyonel ve klinik olarak daha iyi sonuçlara sahip olmadığı ve konservatif tedavi yöntemlerinin sonuçlarının başarılı olduğunu saptandı. İzole ulna cisim kırıkları tedavi yönteminin belirlenmesinde prospektif, çok merkezli ve daha geniş hasta serilerini kapsayan çalışmalara ihtiyaç vardır.

Anahtar Kelimeler: İzole ulna cisim kırığı, konservatif tedavi, cerrahi tedavi

Sorumlu Yazar*: Tolga Tolunay, Gazi Üniversitesi Tıp Fakültesi, Ortopedi ve Travmatoloji Anabilim Dalı, Ankara/ Turkey

E-posta: tolgatolunay@hotmail.com

Received 01.07.2018 accepted 16.07.2018

Doi: $10.18663 / \mathrm{tjcl} .439538$ 


\section{ABSTRACT}

Aim: Conservative and surgical treatment options have been suggested for the treatment of isolated ulna shaft fractures. The aim the study is to research the optimal treatment option for isolated ulna fractures and factors affecting the fracture healing.

Material and Methods: The study included 43 patients who applied to our hospital in 2013-2016 with isolated ulna shaft fractures. Patients were divided into two groups: conservative treatment and surgical treatment. Joint range of motion, grip strength, functional and radiologic results were used for evaluating the results. Pain was evaluated by visual analogue scale (VAS). Grip strength was measured with a hand dynamometer while the patient was sitting and elbow was in 90-degree flexion. Functional tests were evaluated with the Disabilities of the Arm, Shoulder and Hand Score (DASH Score).

Results: 23 patients were in the conservative treatment group and 20 patients were included in the surgical intervention group. No difference was observed in terms of VAS score, grip strength, DASH score and bone union. Average bone union times for the two groups were as following: conservative treatment group, $12 \pm 1.04$ weeks; surgical treatment group, $17 \pm 1.16$ weeks ( $p=0,586)$. No difference was observed between the groups in terms of hand wrist joint range of motion and complications.

Conclusion: Our study showed that patients who were treated by surgical intervention had no functional and clinical superiority to patients with conservative treatment. There is a need for prospective and multicentre studies comprising a larger series of patients for defining the methodology for isolated ulna shaft fractures.

Keywords: Isolated ulna shaft fracture, conservative treatment, surgical treatment

\section{Giriş}

İzole ulna cisim kırıkları göreceli olarak sık görülmeyen kırıklardır, yapılan çalışmalarda insidansı her1000 kişide 0,2 olarak tespit edilmiştir [1]. İzole ulna cisim kırıklarının büyük kısmı ön kolu kaldırırken maruz kalınan darbelere bağlıdır ve minimal deplasman mevcuttur [2]. Ulna kırıkları ile ilgili literatürdeki çoğu çalışma Monteggia kırıklı çıkıkları, olekranon kırıkları ve koronoid proçes kırıklarının tedavisi hakkındadır.

İzole ulna cisim kırıklarının tedavisinde hem konservatif hem de cerrahi metodlar önerilmiştir. Konservatif tedavi seçenekleri kısa veya uzun kol alçı, fonksiyonel breys ve elastik bandajla birlikte kol askısı kullanılması şeklindedir [3-6]. Cerrahi tedavi seçenekleri plak (dinamik kompresyon plağı veya semitübüler) ve intramedüller çivi şeklindedir $[7,8]$.

Konservatif tedavide kaynamama, yanlış kaynama, ağrı, deformite, dirsek ve el bileği eklem hareket açıklığında azalma gibi komplikasyonlar görülebilir $[9,10]$. Cerrahi tedavide de enfeksiyon, kaynamama ve implantın cilt altında hissedilmesine bağlı olarak ikinci cerrahi gereksinimi gibi komplikasyonlar görülebilir [11].

İzole ulna cisim kırıkları diyafizle sınırlı ve deplase olmamış bile olsa seyrini kestirmek çok zordur bu yüzden izole ulna cisim kırıklarının optimal tedavisi hala tartışmalıdır.

Bu çalışmada izole ulna cisim kırığı olup konservatif veya cerrahi olarak tedavi edilen hastalar retrospektif olarak değerlendirildi. Çalışmanın amacı izole ulna cisim kırıklarının optimal tedavisini ve kırık iyileşmesini etkileyen faktörleri araştırmaktır.

\section{Gereç ve Yöntemler}

Çalışmaya 2013-2016 yılları arasında hastanemize başvurmuş, iskelet gelişimini tamamlamış, en az 1 yıl takibi olan ve kriterlere uyan izole ulna cisim kırıklı 43 hasta alındı. Ek yaralanması olan, kırıkları distal radioulnar ekleme $2 \mathrm{~cm}$ yakınlıkta olan, kırığı proksimal 1/3 kısımda olan, kırığı segmental olan ve patolojik kırıkları olan hastalar çalışmaya dahil edilmedi.

Hastaneye başvurduğunda deplase olmayan veya minimal deplasman gösteren izole ulna isim kırığı olan 20 hasta konservatif olarak tedavi edilmişken, diğer 23 hasta da cerrahi olarak tedavi edilmişti.

Röntgen filmleri değerlendirilerek, ön-arka ve yan filmde 10 dereceden az açılanması olan ve \%50'den fazla temasta olan 20 hasta konservatif olarak tedavi edilmişti. Konservatif tedavi edilen 20 hastaya da başlangıçta uzun kol sirküler alçı yapılmış ve parmak hareketlerine hemen başlanarak 1 hafta elevasyon önerilmişti. Hastalarda 3. haftanın sonunda kısa kol atele geçilip dirsek eklemi mobilize edilmişti. Hastaların izleminde 6. haftada kısa kol atel çıkarılıp kısa kol breyse geçilmiş, el bileği eklemi de mobilize edilmiş ve kemik kaynamasına göre 8 ila 14 hafta arasında da breys çıkarılmıştı.

Cerrahi olarak tedavi edilen tüm hastalar genel anestezi altında, turnike eşliğinde opere edilmişti. Klasik subkutanöz ulnar yaklaşımla ekstensör carpi ulnaris ve fleksör karpi ulnaris arasından girilerek kırığa ulaşılmış ve kırık fikasyonu için tüm hastalarda dinamik kompresyon plağı (DCP) kullanılmıştı. 
Ameliyat sonrası tüm hastalara yumuşak doku iyileşmesi için 1 hafta kısa kol atel uygulanmış daha sonra da atel çıkarılıp mobilizasyona başlanmıştı.

Sonuçların değerlendirilmesinde eklem hareket açıklığı, kavrama gücü, fonksiyonel ve radyolojik sonuçlar kullanıldı. Tüm hastalarda hastanın başlangıçtan en az 1 yıl sonraki el bileği dorsifleksiyonu ve palmar fleksiyonu, dirsek ekstansiyon ve fleksiyonu, ön kol supinasyon ve pronasyonu gonyometreyle ölçülüp kaydedildi. Ağrı, vizuel analog skala (VAS) ile değerlendirildi. Kavrama gücüne ise el dinamometresiyle hasta oturuken ve dirsek 90 derece fleksiyonda bakıldı. Fonksiyonel sonuçlara kol, omuz el sorunları skorlaması (DASH Skoru) ile bakıldı [12]. Radyolojik sonuçlar değerlendirilirken ön-arka ve yan filmlerde 3 kortekste kırık çizgisinin görülememesi radyolojik kaynama olarak kabul edildi.

\section{İstatiksel Analiz}

Çalışma grubundaki sayısal ölçümlerin normal dağılım varsayımını sağlayıp sağlamadığı Shapiro Wilk testi ile test edilecek, sayısal verilerden parametrik olanların tanımlayıcı istatistikleri; ortalama \pm standart sapma, non-parametrik olanların ortanca (minimum-maksimum) olarak hesaplanacak, kategorik veriler ise yüzde (\%) olarak verilecektir. Kategorik ölçümlerin gruplar arasında karşılaştırılmasında Ki Kare testi kullanılacak olup, gruplar arasında sayısal ölçümlerin karşılaştırılmasında varsayımların sağlanması durumunda Bağımsız gruplarda $T$ testi, varsayımların sağlanmaması durumunda ise Mann Whitney U testi kullanılacaktır. Anlamlılık sınırı $\mathrm{p}<0,05$ olarak kabul edilecektir. İstatistiksel analiz Statistical Package for Social Sciences" version 20 (IBM Corp., Armonk, NY, USA) programı ile yapılmıştır.

\section{Bulgular}

Çalışmamıza en az 1 yıllık takibi olan 43 hasta dahil edildi. Çalışmaya ulna cisim kırığı ile birlikte ek yaralanması da olan 13 hasta dahil edilmedi. Hastalar konservatif tedavi edilen ve cerrahi olarak tedavi edilen olmak üzere 2 grupta incelendi. Konservatif tedavi edilen grupta 23 hasta, cerrahi tedavi edilen grupta 20 hasta bulunmaktaydı. Hastaların demografik bilgileri ve kırık bilgileri Tablo 1'de özetlendi. Her 2 grup arasında yaş, cinsiyet dağılımı, kırık paterni, yaralanma mekanizması ve kırık lokasyonu açısından fark saptanmadı. Her 2 grup arasında VAS skoru, kavrama gücü, DASH skoru ve kaynama açısından da fark saptanmadı (Tablo 2). Konservatif tedavi edilen grupta kaynama süresi ortalama $12 \pm 1,04$ haftayken cerrahi olarak tedavi edilen grupta kaynama süresi ortalama $17 \pm 1,16$ haftaydı $(p=0,586)$. Her 2 grup arasında dirsek ve el bileği eklem hareket açıklığı ve komplikasyonlar açısından da fark saptanmadı (Tablo 3). Her
2 hasta grubunda da enfeksiyona rastlanmadı. Her 2 gruptan birer örnek vaka Şekil 1 ve Şekil 2 de gösterilmektedir.

\begin{tabular}{|c|c|c|c|}
\hline & Cerrahi Grup & Konservatif Grup & $\mathbf{p}$ \\
\hline Hasta Sayısı (n) & 20 & 23 & \\
\hline Taraf & & & 0,481 \\
\hline -Sağ & 12 & 14 & \\
\hline -Sol & 8 & 9 & \\
\hline Yaş (yıl)* & $36,50(22-51)$ & $40,78(24-56)$ & 0,216 \\
\hline Cinsiyet Dağılımı & & & 0,602 \\
\hline -Erkek & 18 & 19 & \\
\hline -Kadın & 2 & 4 & \\
\hline $\begin{array}{l}\text { Yaralanma } \\
\text { Mekanizması }\end{array}$ & & & 0,948 \\
\hline -Trafik Kazası & 5 & 6 & \\
\hline -Düşme & 4 & 4 & \\
\hline -Saldırı & 8 & 10 & \\
\hline -Diğer & 3 & 3 & \\
\hline Kırık paterni & & & 0,654 \\
\hline -Transvers & 8 & 10 & \\
\hline -Oblik & 12 & 13 & \\
\hline Kırık lokasyonu & & 16 & 0,688 \\
\hline -Distal 1/3 & 13 & 6 & \\
\hline -Orta $1 / 3$ & 5 & 1 & \\
\hline -Proksimal 1/3 & 2 & & \\
\hline \multicolumn{4}{|c|}{ *Ortanca (minimum-maksimum) } \\
\hline
\end{tabular}

\begin{tabular}{|c|c|c|c|}
\hline & $\begin{array}{c}\text { Cerrahi Grup } \\
\text { n }\end{array}$ & $\begin{array}{c}\text { Konservatif Grup } \\
\mathbf{n}\end{array}$ & $\mathbf{p}$ \\
\hline 12. ay DASH skoru* & $13,46 \pm 2,83$ & $13,42 \pm 2,46$ & 0,971 \\
\hline $\begin{array}{l}\text { Kaynama Süresi* } \\
\text { (hafta) }\end{array}$ & $17 \pm 1,16$ & $12 \pm 1,04$ & 0,586 \\
\hline 12. ay kavrama gücü ** & $40,5(34-45)$ & $38,5(33-45)$ & 0,588 \\
\hline $\begin{array}{l}\text { 12. ay Vizuel Analog } \\
\text { Skala (VAS)* }\end{array}$ & $1,91 \pm 0,87$ & $2,08 \pm 1,14$ & 0,315 \\
\hline $\begin{array}{l}\text { Ağrı } \\
\text { - Hiç ağrı yok } \\
\text { - Hafif ağrı }\end{array}$ & $\begin{array}{c}18 \\
2\end{array}$ & $\begin{array}{c}20 \\
3\end{array}$ & \\
\hline $\begin{array}{l}\text { *Ortalama } \pm \text { standart sap } \\
{ }^{*} \text { Ortanca (minimum-m }\end{array}$ & $\begin{array}{l}\text { ma } \\
\text { aksimum) }\end{array}$ & & \\
\hline
\end{tabular}





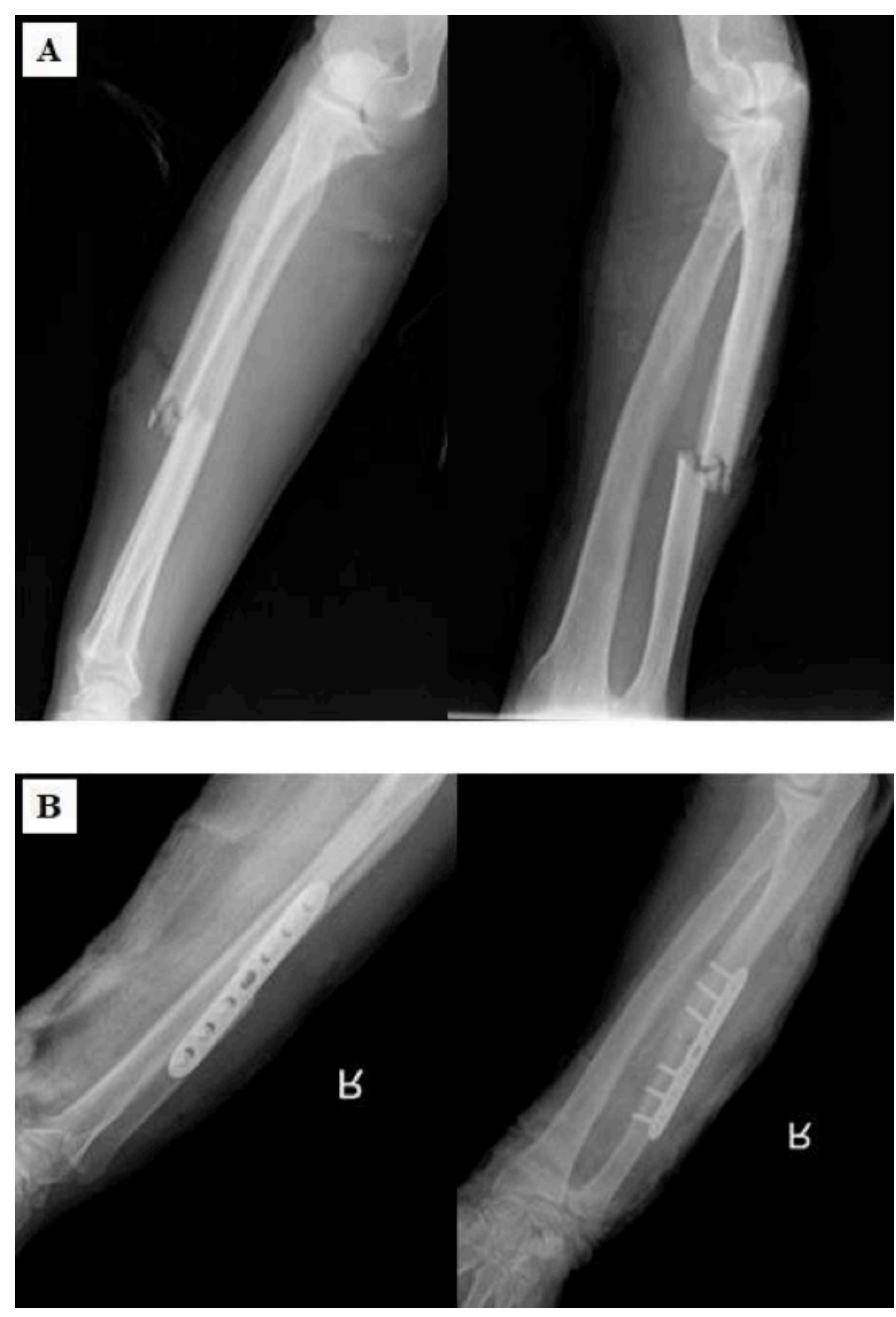

Şekil 1. Ameliyat öncesi (A) ve ameliyat sonrası (B) grafiler

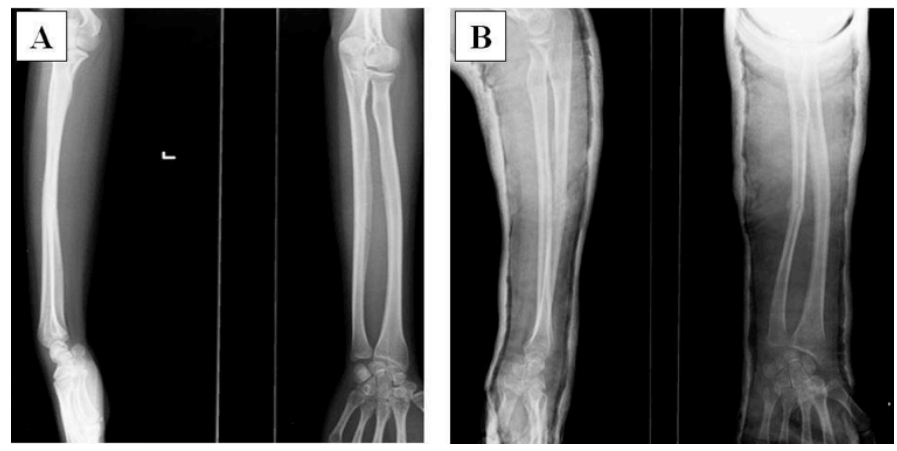

Şekil 2. Alçı öncesi (A) ve alçı sonrası (B) grafiler

\section{Tartışma}

Erişkinlerde ön kol kırıklarının cerrahi tedavi edilmesiyle ilgili genel bir görüş birliği mevcuttur. İzole ulna cisim kırıkları konservatif tedavi düşünülebilecek belki de tek ön kol kırığıdır. Genel tedavi yaklaşımı, kırık angülasyonu 10 dereceden fazla ve temas yüzeyi \%50'den az ise kırığın stabil olmadığı kabul edilip cerrahi uygulanması yönündedir [10,13]. Biz de çalışmamızda bu şekilde hareket ettik.
Konservatif tedavi sırasında immobilizasyon metoduyla ilgili genel görüş birliği mevcut değildir. Yapılan meta analizlerde, farklı 4 immobilizasyon metoduyla ilgili çok küçük farklar bulunmuştur [14]. Gebuhr ve arkadaşları uzun kol alçıyla takip ettikleri 19 hastayı fonksiyonel breysle takip ettikleri 20 hastayla karşılaştırmışlar [9]. Uzun kol alçı ile takip edilen hasta grubunda kaynama süresi ortalama 50 gün iken, fonksiyonel breys ile tedavi edilen hasta grubunda kaynama süresi ortalama 56 gün olarak bulunmuştur. Alçı veya breys çıkarıldıktan sonra el bileği eklem hareket açıklığına $\left(130^{\circ}\right.$ vs $\left.90^{\circ}, \mathrm{P}=.004\right)$ ve ön kol rotasyonuna $\left(158^{\circ}\right.$ vs $\left.138^{\circ}, \mathrm{P}=.071\right)$ bakılmış ve breys grubu daha iyi bulunmuştur ancak uzun dönem takip bildirilmemiştir. Atkin ve arkadaşlarının yaptıkları çalışmada uzun kol alçı yapılan 9 hasta, kısa kol alçı yapılan 14 hasta ve elastik bandaj yapılan 8 hasta radyolojik ve klinik kaynama gerçekleşene kadar takip edilmiş [2]. Tüm gruplardaki kırıklar yaralanmadan 7-8 hafta sonra iyileşmiş ancak elastik bandaj grubundaki 8 hastadan 6'sının tedavisi ağrı nedeniyle alçıyla değiştirilmiştir. Bir başka çalışmada Van Leemput ve arkadaşları başvuru sırasına göre 102 hastayı; Kompresyon bandajı (34 hasta), 6 hafta kısa kol alçı (36 hasta), 3 hafta uzun kolu takiben 3 hafta kısa kol alçı (32 hasta) şeklinde 3 gruba ayırmış [15]. 12 hafta takip sonrası kaynamada gecikme, kaynama süresi, ağı, hareket açıklığı açısından fark bulamamışlardır. Kaynamada gecikmeyi 12 haftanın sonunda radyografide osseöz köprülerin görülmemesi şeklinde tanımlamışlar ve 102 hastanın 13'ünde $(\% 12,7)$ kaynamada gecikme saptamışlardır. Bu hastaların tümü ağrısız ve iyi hareket açıklığına sahipken en son radyolojik ve fonksiyonel durumu bilinmemektedir. Mackay ve arkadaşları yaptıkları sistematik derlemede 33 seriden 1876 hasta değerlendirilmiş ve konservatif tedavinin tüm metodlarında düşük kaynamama oranları saptanmıştır[16]. Kaynama süreleri arasında da belirgin farklar saptanmamışken, hareket açıklığı erken mobilize olan ve fonksiyonel breys gruplarında daha iyi olmasına karşın zamanla bunun aynı kalıp kalmadığı bilinmemektedir.

Kaynama süresi elastik bandaj grubunda daha kısa bulunurken fonksiyonel breys ve kısa kol alçı grubunda uzun kol alçıya nazaran çok az daha uzun bulunmuştur. Erken literatürün aksine uzun kol alçı ve kısa kol alçı arasında fark bulunamamıştır. Kaynamama oranları tüm gruplar için düşük bulunmuştur. Fonksiyonel sonuçlar fonksiyonel breys ve erken mobilizasyon gruplarında daha iyiyken uzun kol alçıda daha kötü bulunmuştur. Ancak tüm bu farklar çok azdır ve klinik olarak önemsiz olarak kabul edilmiştir. Biz de çalışmamızda 3 immobilizasyon metodunu ardışık olarak kullandık ve iyi fonksiyonel sonuçlar elde ettik. 
Dymond ve arkadaşlarının yaptığı çalışmada başlangıçtaki kırık deplasmanı kemik çapının \%50'sinden azsa interosseöz membranın yırtılmadığı ve kırı̆ın rotasyonel olarak stabil kabul edilmiştir [14]. Zych ve Brakenbury'nin yaptığı çalışmada başlangıçtaki kırık açılanması 10 dereceden azsa sonrasında açılanmanın artmadığı ve rotasyonda kayıp gelişmediği saptanmıştır [3,17]. Bizde bu kriterlere göre bu değerleri aşan hastaları cerrahi olarak tedavi etmiştik. Cerrahi tedavi için değişik plaklar ve son zamanlarda popüler olan intramedüller çiviler mevcuttur [18]. Ancak biz tüm hastaları literatürde de etkinliği kanıtlanmış olan kompresyon plakları ile tedavi olanlar arasından seçtik. Yapılan çalışmalarda cerrahi tedavinin en önemli avantajlarl; fonksiyonun erken restorasyonu ve kırık çevresindeki el bileği ve dirsek eklemlerinin erken mobilizasyonudur. Çalışmamızda da cerrahi grupta dirsek ve el bileği eklem hareket açıklığı daha iyiydi ancak istatiksel olarak anlamlı fark bulunamadı. Cerrahi tedavinin en önemli dezavantajı sonrasında gelişebilecek implant çıkarma gereksinimidir. Çalışmamızda bunu değerlendirmedik. Ağrı, cerrahi grupta implanta ve konservatif grupta ise iyileşme problemlerine bağlı olabilir. Çalışmamızda cerrahi grupta hafif ağrı daha fazlaydı ancak istatiksel olarak anlamlı fark saptanmadı. İzole ulna cisim kırıklarının tedavisinde kaynamama, yanlış kaynama, sekonder deplasman, kompartman sendromu, sinostoz ve hareket açıklığında azalma gibi komplikasyonlar görülebilir. Çalışmamızdaki komplikasyon oranının diğer çalışmalarla benzer olduğunu gördük. Literatürde $\% 1$ ila $\% 15$ oranında yanlış kaynama oranları bildirilmesine karşın çalışmamızda yanlış kaynama saptanmamıştır [10]. Kaynamama oranları literatürde $\% 0$ ila $\% 30$ oranında bildirilmiştir [10]. İzole ulna kırıklarında kaynamamaya sebep olan faktörler çelişkili ve multifaktoryeldir. Kaynamamaya sebep olan faktörler olarak kırık tipi (parçalı kırıklar), kırık lokasyonu, başlangıçtaki deplasman miktarı, yaralanma mekanizması, cerrahi tedavi, yaş ve cinsiyet suçlanmasına karşın bu faktörlerin etkisinin olmadığını bildiren yayınlar da mevcuttur $[3,12,19]$. Çalışmamızda cerrahi grupta 2 kaynamama, konservatif grupta 1 kaynamama vakası saptandı.

Çalışmanın en önemli kısıtılıkları; retrospektif olması, tek merkez hastalarının değerlendirilmesi ve vaka sayısının göreceli olarak azlı̆̆ıdır.

\section{Sonuç}

İzole ulna cisim kırıklarını değerlendiren çalışmalar olmasına karşın tam bir görüş birliği yoktur. Son yıllarda endüstrinin getirdiği baskıyla çoğu kırıklarda cerrahi tedaviye eğilim artmıştır. Ancak çalışmamızda cerrahi olarak tedavi edilen hastaların konservatif olarak tedavi edilen hastalardan fonksiyonel ve klinik olarak daha iyi sonuçlara sahip olmadığını saptadık ve literatürde tam bir görüş birliği olmasa da kabul edilen konservatif tedavi yöntemlerinin sonuçlarının başarılı olduğunu saptadık. Ancak izole ulna cisim kırıkları tedavi yönteminin belirlenmesinde prospektif, çok merkezli ve daha geniş hasta serilerini kapsayan çalışmalara ihtiyaç vardır.

\section{Etik Onay}

Araştırma için Yıldırım Beyazıt Üniversitesi Yenimahalle Eğitim ve Araştırma Hastanesi Klinik Araştırmalar Etik Kurulu'ndan etik kurul onayı 2018/06/10 karar sayısı ile alındı.

\section{Çıkar çatışması / finansal destek beyanı}

Bu yazıdaki hiçbir yazarın herhangi bir çıkar çatışması yoktur. Yazının herhangi bir finansal desteği yoktur

\section{Kaynaklar}

1. Handoll $\mathrm{HH}$, Pearce P. Interventions for treating isolated diaphyseal fractures of the ulna in adults. Cochrane Database Syst Rev 2012; 13: CD000523. doi:10.1002/14651858.CD000523. pub4. Review.

2. Atkin DM, Bohay DR, Slabaugh P, Smith BW. Treatment of ulnar shaft fractures: a prospective, randomized study. Orthopedics 1995; 18: 543-47.

3. Corea JR, Brakenbury PH, Blakemore ME. The treatment of isolated fractures of the ulnar shaft in adults. Injury 1981; 12: 365-70.

4. Du Toit FP, Grabe RP. Isolated fractures of the shaft of the ulna. S Afr Med J 1979; 56: 21-5.

5. Sarmiento A, Latta LL, Zych G, McKeever P, Zagorski JP. Isolated ulnar shaft fractures treated with functional braces. J Orthop Trauma 1998; 12: 420-24.

6. Pollock FH, Pankovich AM, Prieto JJ, Lorenz M. The isolated ulnar shaft fracture: treatment without immobilization. J Bone Joint Surg Am 1983; 65: 339-42.

7. Chapman MW, Gordon JE, Zissimos AG. Compression plate fixation of acute fractures of the diaphyses of the radius and ulna. J Bone Joint Surg Am 1989; 71: 159-69.

8. Boriani S, Lefevre C, Malingue E, Bettelli G. The Lefevre ulnar nail. Chir Organi Mov 1991; 76: 151-55.

9. Gebuhr P, Hölmich P, Orsnes T, Soelberg M, Krasheninnikoff M, Kjersgaard AG. Isolated ulnar shaft fractures: comparison of treatment by a functional brace and long-arm cast. J Bone Joint Surg Br 1992; 74: 757-59. 
10. Coulibaly MO, Jones CB, Sietsema DL, Schildhauer TA. Results of 70 consecutive ulnar night stick fractures. Injury 2015; 46 1359-66.

11. Stern PJ, Drury WJ. Complications of plate fixation of forearm fractures. Clin Orthop Relat Res 1983; 175: 25-29

12. Hudak PL, Amadio PC, Bombardier C. Development of an upper extremity outcome measure: the DASH (disabilities of the arm, shoulder and hand). Am J Ind Med 1996; 29: 602- 8

13. Szabo RM, Skinner M. Isolated ulnar shaft fractures: retrospective study of 46 cases. Acta Orthop Scand 1990; 61: 350-52.

14. Dymond IW. The treatment of isolated fractures of the distal ulna. J Bone Joint Surg Br 1984; 66: 408-10.

15. Van Leemput T, Mahieu G. Conservative management of minimally displaced isolated fractures of the ulnar shaft. Acta Orthop Belg 2007; 73: 710-13.
16. Mackay $D$, Wood $L$, Rangan A. The treatment of isolated ulnar fractures in adults: a systematic review. Injury 2000; 31: 565-70.

17. Zych GA, Latta LL, Zagorski JB. Treatment of isolated ulnar shaft fractures with prefabricated functional fracture braces. Clin Orthop Relat Res 1987; 219: 194-200.

18. Saka G,Saglam N,Kurtulmus T,Avcı CC,Akpınar F,Kovacı H,Celik A .New interlocking intramedullary radius and ulna nails for treating forearm diaphyseal fractures in adults: A retrospective study. Injury 2014; 45: 16-23.

19. Leung F, Chow SP. A prospective, randomized trial comparing the limited contact dynamic compression plate with the point contact fixator for forearm fractures. J Bone Joint Surg Am 2003; 8: 2343-48. 